\title{
The role of accreditation in 21 st century health professions education: report of an International Consensus Group
}

\author{
Jason R. Frank ${ }^{1,2^{*}}$, Sarah Taber ${ }^{1}$, Marta van Zanten ${ }^{3}$, Fedde Scheele ${ }^{4,5,6}$, Danielle Blouin ${ }^{7}$ and on behalf of the
} International Health Professions Accreditation Outcomes Consortium

\begin{abstract}
Background: Accreditation is considered an essential ingredient for an effective system of health professions education (HPE) globally. While accreditation systems exist in various forms worldwide, there has been little written about the contemporary enterprise of accreditation and even less about its role in improving health care outcomes. We set out to 1) identify a global, contemporary definition of accreditation in the health professions, 2) describe the relationship of educational accreditation to health care outcomes, 3) identify important questions and recurring issues in twenty-first century HPE accreditation, and 4) propose a framework of essential ingredients in present-day HPE accreditation.
\end{abstract}

Methods: We identified health professions accreditation leaders via a literature search and a Google search of HPE institutions, as well as by accessing the networks of other leaders. These leaders were invited to join an international consensus consortium to advance the scholarship and thinking about HPE accreditation. We describe the consensus findings from the International Health Professions Accreditation Outcomes Consortium (IHPAOC).

Results: We define accreditation as the process of formal evaluation of an educational program, institution, or system against defined standards by an external body for the purposes of quality assurance and enhancement. In the context of HPE, accreditation is distinct from other forms of program evaluation or research. Accreditation can enhance health care outcomes because of its ability to influence and standardize the quality of training programs, continuously enhance curriculum to align with population needs, and improve learning environments. We describe ten fundamental and recurring elements of accreditation systems commonly found in HPE and provide an overview of five emerging developments in accreditation in the health professions based on the consensus findings.

Conclusions: Accreditation has taken on greater importance in contemporary HPE. These consensus findings provide frameworks of core elements of accreditation systems and both recurring and emerging design issues. HPE scholars, educators, and leaders can build on these frameworks to advance research, development, and operation of high-quality accreditation systems worldwide.

Keywords: Accreditation, Curriculum, Assessment, Learning environment, Quality improvement, Outcomes

\footnotetext{
* Correspondence: jfrank@royalcollege.ca

'Office of Specialty Education, Royal College of Physicians and Surgeons of Canada, Ottawa, Canada

${ }^{2}$ Department of Emergency Medicine, University of Ottawa, Ottawa, Canada

Full list of author information is available at the end of the article
}

(C) The Author(s). 2020 Open Access This article is licensed under a Creative Commons Attribution 4.0 International License, which permits use, sharing, adaptation, distribution and reproduction in any medium or format, as long as you give appropriate credit to the original author(s) and the source, provide a link to the Creative Commons licence, and indicate if changes were made. The images or other third party material in this article are included in the article's Creative Commons licence, unless indicated otherwise in a credit line to the material. If material is not included in the article's Creative Commons licence and your intended use is not permitted by statutory regulation or exceeds the permitted use, you will need to obtain permission directly from the copyright holder. To view a copy of this licence, visit http://creativecommons.org/licenses/by/4.0/. The Creative Commons Public Domain Dedication waiver (http://creativecommons.org/publicdomain/zero/1.0/) applies to the data made available in this article, unless otherwise stated in a credit line to the data. 
A strong case is made that the present content, organisation, and delivery of health professionals' education have failed to serve the needs and interests of patients and populations.

-Richard Horton, Lancet 2010 [1]

\section{Background}

Effective accreditation is considered an essential ingredient for any system of health professions education (HPE) [2] At the present time, HPE accreditation is undergoing unprecedented scrutiny and change worldwide. While some form of quality monitoring activity is arguably as old as modern medical schools, $[3,4]$ seminal reports on HPE reform have driven the evolution of accreditation in an accelerating fashion. The Flexner Report (1910) [5] led to the shuttering of dozens of North American medical schools, as well as to changes to curriculum, philosophy of education, and oversight. The 1988 Edinburgh Declaration [6] sought to realign HPE to societal needs and it drove reforms in instructional methods, faculty development, and settings for training. The 2010 Lancet Commission on the Education of Health Professionals for the twenty-first Century [7] demanded the worldwide change to competency-based HPE to better meet the needs of local populations [8]. In 2012, the Accreditation Council for Graduate Medical Education (ACGME) implemented these kinds of changes in American residency education by reorienting US accreditation with graduate outcomes instead of processes [9]. In 2013, the Canadian Residency Accreditation Consortium (CanRAC) also moved to fundamentally overhaul its philosophy, activities, infrastructure, and standards for a more contemporary approach to accreditation [10]. Why has there been all this attention on accreditation reform in recent years? Those highlighting the failings of HPE have advocated for greater attention for accreditation systems. The Lancet Commission, for example, has spotlighted perceptions of ill-prepared graduates in poorly designed HPE systems [7]. The outcomes work of David Asch and others has highlighted unacceptable variations in graduate competence produced by current programs [11-14]. Among the critical reforms of the twenty-first century is a growing call to update HPE accreditation to ensure quality training produces high-quality graduates $[9,15]$.

Accreditation systems provide oversight and guidance to health professions training programs and articulate a model of quality training to produce practitioners to meet societal health needs [2,15]. For such a critical function in a professional education system, little has been written to describe the role, elements, impact, and evolution of HPE accreditation. Even less has been done to link accreditation practices to the outcomes of training programs.

\section{Purpose}

To begin a twenty-first century dialogue about the future of accreditation in the health professions, we recognized a need to review the existing literature on accreditation, examine systems worldwide, and develop consensus frameworks on which to build the next generation of accreditation systems. We describe the efforts of an international consensus consortium to 1) identify a global, contemporary definition of accreditation in the health professions, 2) describe the relationship of educational accreditation to health care outcomes, 3) identify important questions and recurring issues in twenty-first century HPE accreditation, and 4) propose a framework of essential ingredients in present-day HPE accreditation.

\section{Methods}

To address these goals, we identified health professions accreditation leaders via a literature search and Google search of HPE institutions, as well as by accessing the networks of other leaders using snowball sampling [16]. We specifically sought out accreditation leaders and scholars from multiple health professions, as well as those with perspectives from across the continuum of a health professional's career. These leaders were invited to join an international consensus consortium to advance the scholarship and thinking about HPE accreditation-called the International Health Professions Accreditation Outcomes Consortium (IHPAOC, pronounced "epoch").

We then organized a series of issue identification and consensus activities. We convened the 1st World Summit on Accreditation Outcomes in conjunction with the International Conference on Residency Education in Calgary, Canada in 2013, and a 2nd World Summit in conjunction with the Association for Medical Education in Europe conference in Basel, Switzerland in 2018. At these Summits, we used an iterative group process to identify themes related to the current state of, and future directions for, HPE accreditation. Table 1 lists the breadth of representation at the Summits. We subsequently organized regular (approximately six times per year) international calls and subgroups for the Consortium to further explore the issues identified at the Summit. As part of this process, we developed a series of papers to capture the consensuses formed on the subthemes identified. Each paper was discussed and reviewed by all members of the Consortium. 
Table 1 Breadth of representation at 2013 and 2018 World Summits

\begin{tabular}{|c|c|c|c|}
\hline & $\begin{array}{l}\text { Total } \\
\text { Registrants }\end{array}$ & Countries Represented & Organizations Represented \\
\hline \multirow[t]{2}{*}{2013} & 82 & 10 & 41 \\
\hline & & $\begin{array}{l}\text { United States, Australia, Netherlands, Germany, China, Taiwan, } \\
\text { Oman, Canada, Qatar, Barbados }\end{array}$ & $\begin{array}{l}\text { Accreditation Council for Graduate Medical Education, Alberta } \\
\text { Health Services, ANZCA, Association of Faculties of Medicines of } \\
\text { Canada, Australian Medical Council, Australian National University } \\
\text { Medical School, Canadian Medical Association, Catharina Hospital } \\
\text { Eindhoven, Children's Hospital of Eastern Ontario, China Medical } \\
\text { University (Taiwan), Collège des médecins du Québec, College of } \\
\text { Family Physicians of Canada, College of Physicians \& Surgeons of } \\
\text { Alberta, Committee on the Accreditation of Canadian Medical } \\
\text { Schools, Dalhousie University, Foundation for Advancement of } \\
\text { International Medical Education and Research, Hôpital de } \\
\text { Montréal pour enfants, Maimonides Infants and Children's } \\
\text { Hospital of Brooklyn, Mayo Clinic, McGill University, McMaster } \\
\text { University, Medical Case Center; Karolinska Institutet, Memorial } \\
\text { University, Northern Ontario School of Medicine, Oakland } \\
\text { University, OLVG Teaching Hospital, Oman Medical Specialty } \\
\text { Board, Queen's University, Ross University, Royal Australasian } \\
\text { College of Physicians, Royal College of Physicians and Surgeons } \\
\text { of Canada, Sidra Medical and Research Center, The Ottawa } \\
\text { Hospital, The Royal Dutch Medical Association, Tom Baker Cancer } \\
\text { Centre, University of Alberta, University of British Columbia, } \\
\text { University of Calgary, University of Manitoba, University of } \\
\text { Saskatchewan, University of Toronto, University of Western } \\
\text { Ontario }\end{array}$ \\
\hline
\end{tabular}

$2018 \quad 45 \quad 15$

United States, Australia, United Kingdom, Canada, Oman, Germany, Netherlands, Singapore, Finland, Austria, United Arab Emirates, South Korea, Cameroon, Sudan, France

\section{1}

Accreditation Council for Graduate Medical Education, Association of Faculties of Medicine of Canada, Australian Dental Council, Australian Medical Council, Australian National University, Committee on Accreditation of Canadian Medical Schools, Dieter Scheffner Center for Medical Education, Educational Commission for Foreign Medical Graduates, Foundation for Advancement of International Medical Education and Research, Jhpiego, Johns Hopkins, Korea University, Massachusetts General Hospital, Medical Specialties Council Netherlands, Memorial University, Michigan Medicine, National Cancer Center Singapore, OLVG hospital/NU medical center, Oman Medical Specialty Board, Opportunities In Africa, Pro Medico, Royal College of Physicians and Surgeons of Canada, Sudan Medical Specialization Board, Tan Tock Seng Hospital, The Royal Dutch Medical Association, Ty Dresden, Western Sydney University, United Arab Emirates University, Université Lumière, University of Calgary, University of Plymouth,
In this paper, on behalf of the IHPAOC, we offer an overview of the consensus discussions on the fundamental issues and elements of HPE accreditation.

\section{Results: contemporary issues in HPE accreditation What is accreditation in HPE?}

Accreditation can be considered a societal enterprise that is fundamental for both effective HPE and effective health care, but there is no universal agreement on its definition. It has variously been described as a form of quality assurance (QA), an enterprise of continuous quality improvement (CQI), a form of program evaluation, and various combinations of the above. The World Federation for Medical Education (WFME), for example, espouses the following:
Accreditation is the certification of the suitability of medical education programmes, and of the competence of medical schools in the delivery of medical education [17].

Similarly, the International Association of Medical Regulatory Authorities uses this statement:

Accreditation is the process by which a credible, independent body assesses the quality of a medical education program to provide assurance that it produces graduates that are competent to practise safely and effectively under supervision as interns (or equivalent), and have been provided with an appropriate foundation for lifelong learning and further training in any branch of medicine [18]. 
The US National Academy of Sciences, Engineering and Medicine defines accreditation in terms of health workforce planning:

The purpose of accreditation is to build a competent health workforce by ensuring the quality of training taking place within those institutions that have met certain criteria. ... Accreditation is a tool for monitoring and ensuring such quality [15].

Key features that arose in the discussions included the following: the idea that accreditation is a special kind of evaluation targeting a program, an institution, or a system; accreditation involves a comparison against defined standards; accreditation is usually a partnership between the target of the process and some kind of third-party institution; and the view that modern accreditation involves both quality assurance and quality improvement. The IHPAOC members sought a more precise definition of accreditation that both addressed all of these issues and applied to the continuum of HPE. To that end, we developed and adopted the following definition:

Accreditation in the health professions is the process of formal evaluation of an educational program, institution, or system against defined standards by an external body for the purposes of quality assurance and continuous enhancement.

IHPAOC also adopted the following goal statement for HPE accreditation:

Accreditation contributes to ensuring high quality training for a competent workforce prepared to serve societal needs effectively.

\section{How does accreditation relate to program evaluation or research in HPE?}

Accreditation, program evaluation, and medical education research can sometimes be overlapping endeavours, with shared methods. Table 2 compares these three enterprises.
Accreditation can be mandated by government or another oversight body or it can be part of a profession's self-regulation. Meanwhile, program evaluation and research are usually elective activities. Funding for accreditation can be part of a government or regulatory scheme, or it can be from the profession itself. Funding for program evaluation and research come from a wider array of sources, such as grants, endowments, or institutional budgets. In terms of its purpose, accreditation is sometimes seen as a special class of program evaluation, in that programs/curricula/institutions are the evaluands being examined. In the case of accreditation, the evaluation is for the purpose of determining alignment with defined standards from an external body. By contrast, program evaluation and research each employ a vast array of tailored questions, methods, data, and purposes. Accreditation is a special enterprise, with a specific, constrained scope and purpose $[19,20]$.

\section{What is the role of accreditation in HPE?}

Accreditation's dual functions of QA and CQI can improve HPE through enhanced training and improved graduate abilities. Table 3 illustrates the spectrum of these QA and CQI perspectives. These two perspectives can often co-exist in many accreditation systems.

\section{Accreditation as quality assurance}

Accreditation is often cited as an essential ingredient in HPE systems: it is a process to ensure that high quality education produces competent graduates to serve a population's needs. Figure 1 describes how accreditation connects to the "links in the quality chain" of the health professions. In this sense, accreditation is a form of QA in which programs and institutions and/or systems are measured against pre-defined expected characteristics. A decision is made after an accreditation review as to whether the program/institution has met the standard. This mode of accreditation can be high stakes: careers, programs, funding, reputations, services, and learner advancement can all depend on the review's findings. This is a summative view of accreditation:

Table 2 Accreditation, program evaluation, and research in health professions education

\begin{tabular}{|c|c|c|c|}
\hline & Accreditation & Program Evaluation & Research in HPE \\
\hline Mandate & $\begin{array}{l}\text { Ensure safe, high-quality programs, institutions, } \\
\text { or systems } \\
\text { Often mandated }\end{array}$ & Accountability to decision makers and improvement & $\begin{array}{l}\text { Generate new } \\
\text { knowledge }\end{array}$ \\
\hline Purpose & $\begin{array}{l}\text { Quality assurance and continuous } \\
\text { improvement of training }\end{array}$ & $\begin{array}{l}\text { Understanding of context, inputs, implementation, outcomes, } \\
\text { impact, or value }\end{array}$ & $\begin{array}{l}\text { Scholarship } \\
\text { Advancement of } \\
\text { field }\end{array}$ \\
\hline Funding & $\begin{array}{l}\text { Often government or professional regulatory } \\
\text { body }\end{array}$ & Variable & Variable \\
\hline Methodologies & \multicolumn{3}{|c|}{ A wide variety of quantitative and/or qualitative methods are shared } \\
\hline
\end{tabular}


Table 3 Accreditation as quality assurance and continuous quality improvement

\begin{tabular}{lll}
\hline & Quality Assurance & Continuous Quality Improvement \\
\hline Goal & How can we ensure achievement of minimum standards? & How can we promote excellence and innovation? \\
Characteristics & What is below the standard? & What can be done to improve? \\
& Quality judgments & Formative \\
& Measurement against predefined requirements and thresholds & Fctionable feedback \\
& Preventing harm to learners and patients & Dissemination of innovations, leading practices, and "next" practices \\
& Culture of episodic, high-stakes evaluation & Culture of continuous enhancement \\
& Audit model & Coaching model \\
\hline
\end{tabular}

accreditation as bulwark to quality and sheriff for suboptimal training $[2,15,17,18,21-27]$.

In its regulatory QA function, accreditation can ensure learning environments are safe and effective for learners. By promoting adherence to minimum standards, accreditation can even prevent negative environments and practises from being perpetuated, preventing harm to learners and patients alike. QA can also focus on minimum thresholds for the quality of curriculum, instructional methods, and assessment practices. Accreditation, in its QA mode, contributes to keeping the profession, its learners, and its patients safe. Accreditation fulfills a kind of professional accountability and helps to ensure public confidence in self-regulated professions [27].

\section{Accreditation as continuous quality improvement}

Others describe accreditation as truly a formative process of CQI: programs, institutions, or systems are measured against standards to provide feedback on areas of strength and areas that can be improved [28-37].
Collecting accreditation information in program or institutional portfolios or "report cards" can support ongoing monitoring and improvement of key aspects of education [20, 36, 37]. Ever-evolving third-party standards can be deployed to identify and ameliorate weaknesses in HPE institutions and curricula, with the intention of creating a culture of continuous enhancement. In this way, accreditation can prevent the "fossilization" of curriculum (something Abrahamson called "curriculum ossification") [38]. Accreditation processes, using onsite surveyors and peer review, can also disseminate innovations and good practices. In the mode of accreditation as CQI, society is served by ensuring a continuous quest for the most effective curricula to produce the best possible graduates.

\section{How does accreditation contribute to health care outcomes?}

In creating standards of educational quality, the accreditation process communicates the values of a profession

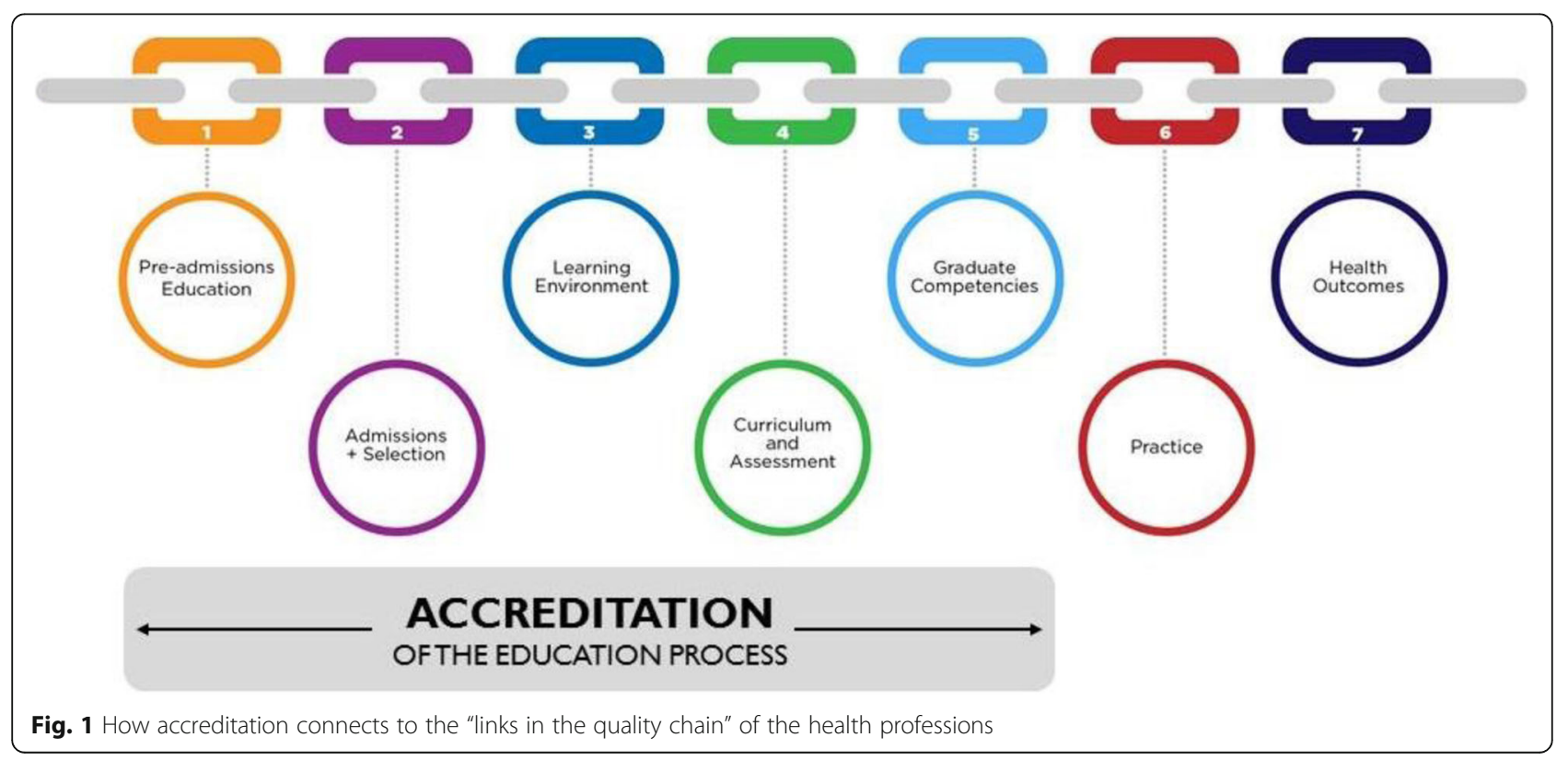


or professional community. The creation of these standards should consider societal needs for the health professions, aligning them with desired health care outcomes [2]. There is clear evidence that the quality of HPE has a powerful impact on graduate outcomes. Work by Asch [11],Tamblyn [39], Bordage [40], and others clearly demonstrates the profound and permanent impact of the educational setting on graduate abilities and practice patterns. Evidence also suggests that there are factors contributing to physician performance variation that occur outside of clinical skills and knowledge acquisition, such as organizational and systemic factors, thereby making the case for a holistic accreditation system to examine these factors in the learning environment [9, 14].

The emerging work of authors such as Braithwaite and colleagues has provided validity evidence for the positive impact of accreditation activities on desired clinical and institutional outcomes [41-43]. In HPE systems, accreditation contributes to a virtual "value chain" through its impact on the quality of training. By ensuring that minimum requirements are met, accreditation can decrease variation in education and practice, and promote adoption of accepted innovations. Accreditation, through both QA and CQI, can influence the quality of learner selection, curriculum content, teaching activities, learning environments, assessment systems, and ultimately the competence and practice of graduates. It is the practice of these graduates that directly impact health care outcomes. Therefore, accreditation is an essential ingredient in an effective health care system $[2,7,9,11]$.

\section{What are the common core elements of accreditation systems in HPE?}

Accreditation systems around the world are numerous and varied. Each has evolved in its unique context and is composed of unique features [44]. IHPAOC identified the need for a common typology of core elements of accreditation systems, and so proposed a simple framework. The 10 core elements are listed in Table 4. Accreditation systems across the continuum of HPE typically have these components, although with great variation. Design features related to these various elements are elaborated in another IHPAOC paper by Taber et al. [45].

For each of these elements, it should be noted that there is no clear evidence or consensus as to which features are essential for accreditation to contribute to quality outcomes. However, the power of these core elements is in their promise as a kind of lingua franca for accreditation system design and comparison.
Table 410 core elements of accreditation systems Accreditation system element and definition

1. Mandate: The role and purpose of the accrediting body in reviewing the quality of educational programs, institutions, or systems.

2. Accreditation standards (Criteria, Requirements): Measures or generally accepted benchmarks used in making decisions about the quality of a program, institution, or system.

3. Application for accreditation: The process of reviewing an initial request for accreditation by a program seeking to demonstrate compliance with established standards, and which results in a decision about whether to grant new (first-time) accreditation.

4. Self-study (self-evaluation, self-assessment): The internal process of reflection undertaken by a program, institution, or system to evaluate compliance with externally established standards.

5. External assessment of standards: The process of determining the level of compliance of a program, institution, or system with established accreditation standards, undertaken by individuals external to the program, institution, or system.

6. Accreditation reports: The final report by external evaluators regarding the level of compliance of the program, institution, or system with established standards.

7. Accreditation decision: The final decision on accreditation status, and its associated follow-up, as determined by the accrediting body.

8. Accreditation cycle: The phases of an accreditation process dictating how often each program, institution, or system is re-evaluated for compliance with the standards, including the types of phases and activities in the process and any follow-up activities that must occur between external assessments.

9. Site review model: The approach used by the accrediting body in determining the composition of its external site review team, as well as processes for recruiting, assigning, training, and assessing team members.

10. Accreditation system administration: The approaches used by the accrediting body to support the administration and operationalization of the accreditation process; this component includes the business model, the technology used (if any), system review and improvement (including research and scholarship), and oversight and risk management.

Trends and tensions: emerging developments in HPE accreditation?

As a final task, IHPOAC participants highlighted several trends and tensions as HPE evolves in the unique context of the twenty-first century.

1. Summative vs. formative? QA vs. CQI? The first overarching theme deals with the tension between the QA and CQI functions of accreditation systems. This is a perennial debate; one that continues to this day. While both perspectives on the role of accreditation involve the comparison of educational quality data to a standard, the CQI view goes beyond making a summative judgment based on the identified gaps. CQI accreditation attempts to provide detailed information on how to enhance a program or institution, perhaps even coaching on how to achieve a higher level of quality. This dichotomy is closely related to another debate as to 
whether accreditation systems should be fundamentally formative (information provided for the express purpose of improvement of the target) or summative (judgment made on the merit or status of a target). IHPAOC members identified that accreditation designers should explicitly identify and communicate the goals of the process, as well as how those goals relate to QA vs. CQI [45].

2. Continuous vs. episodic? Participants in the Summit identified a shift from episodic, occasional "biopsies" of programs/institutions/systems to more continuous sampling of information on the state of those targets. Once again, the IHPAOC members felt that this issue should be tailored to the purpose of the accreditation system. Episodic sampling tended to be higher stakes and to involve expensive periodic information gathering; however, it allowed low periods between accreditation activities. In some ways, episodic reviews could be less disruptive to educational work. On the other hand, the argument for continuous elements in accreditation processes is that they allow accreditors to monitor changes in HPE over time, intervene early to ensure adherence or improvement, and ensure that conversations about quality and good practices are always present in programs, institutions, and systems. Adding to this discussion, the IHPAOC paper authored by Akdemir et al. uses the seven core values set out in a study of government oversight to examine three medical education systems [46].

3. Onsite visits vs. document reviews? Another issue-one related to variations in accreditation practices-relates to the methodology of data gathering. Document reviews are efficient ways to gather information on an educational target, comparing what is described to accreditation standards. However, others advocate for more expensive, and resource-intensive, onsite reviews (sometimes called "surveys") by expert peer or hired reviewers who look for evidence of adherence to standards in the actual educational environment. Onsite reviews have the obvious advantages of first-hand information, contact with multiple participants, and access to richer sources of information [45].

4. Peer review vs. accreditation expert review? Who should conduct accreditation reviews? IHPAOC members identified a debate between hired experts who are dedicated to accreditation full time and selected peer reviewers who provide authentic perspectives reflective of their own experiences. With no evidence to guide the choice, Summit participants concluded that the decision should be based on philosophy and practicality. For example: Is authenticity or expertise more important? What is the availability of experts vs. peers? Is crossfertilization of innovation important $[46,47]$ ?

5. Outcomes vs. process measures? The final tension occurring in debates among accreditors worldwide is related to how much to weight standards to process (e.g., Does this teaching occur?) vs. outcomes (e.g., Can graduates perform this surgery?). Process measures were characterized as surrogates for the desired outcome in some cases, and they are often easier to measure than outcome measures, which can be complex, temporally distant, and confounded. Summit participants identified a distinct shift to greater, but not exclusive, use of outcome measures for accreditation standards as more data become available [48].

\section{Discussion}

HPE is often cited as an essential component of the health care system of any nation. However, there is evidence that HPE suffers from poor outcomes and unacceptable variation in graduate abilities. There is also evidence of patient harm. Accreditation has been identified as a solution to these challenges facing the health professions, one that can promote both adherence to minimum standards and continuous improvement. There is now an evidence base that supports accreditation as "links in a quality chain" (Fig. 1) and measuring educational activities versus standards has a powerful driving affect on HPE effectiveness. Accreditation is essential to the vitality of a profession and ensures graduates are safely and effectively prepared for contemporary practice $[2-4,7,9,15,18,21,49]$.

The founding of the IHPAOC and the launch of the 1st and 2nd World Summits on Accreditation Outcomes provided a unique opportunity to advance practice and knowledge about accreditation as an enterprise within HPE. The consensus network worked to define HPE accreditation, as well as its role in HPE systems. In doing so, we identified early evidence to guide the design and practice of an accreditation enterprise. Accreditation is limited by lack of a large evidence base and challenged by several philosophical and practical debates and controversies, as well as the lack of a common framework of core elements. This global network has now proposed direction for these core elements and the issues facing HPE accreditation as it continues to evolve. There is an urgent need to build on this work to evaluate and innovate on HPE accreditation to enhance training and, thereby, enhance care. 


\section{Conclusion}

HPE accreditation plays a fundamental role in the health workforce for the nations of the world. We report the findings of an international consortium on HPE accreditation that educators around the world can build upon to advance the quality of HPE. By adopting a common definition and identifying recurring issues and the taxonomy of elements, we can begin to compare, learn from, and build upon the diversity of HPE accreditation systems worldwide.

\section{Abbreviations \\ ACGME: Accreditation Council for Graduate Medical Education; CQI: Continuous quality improvement; HPE: Health professions education; IHPAOC: International Health Professions Accreditation Outcomes Consortium; QA: Quality assurance; WFME: World Federation for Medical Education}

\section{Acknowledgements}

The authors would like to thank the members of the International Health Professions Accreditation Outcomes Consortium for their contributions to the ideas in this paper, and everyone who reviewed and provided feedback to this project. Many thanks to Laura K Molgaard and Parveen Wasi for their helpful and critical review of this paper.

\section{About this supplement}

This article has been published as part of BMC Medical Education Volume 20 Supplement 1, 2020: Current themes and challenges facing HPE

accreditation in the twenty-first century. The full contents of the supplement are available online at https://bmcmedicaleducation.biomedcentral.com/articles/supplements/volume-20-supplement-1.

\section{Authors' contributions}

JRF drafted the manuscript. ST contributed to outlines, earlier versions of the text, and specific sections. MVZ, FS, and DB made comments, suggestions, and critical revisions and additions to the manuscript. All authors approved the submission of the final manuscript.

\section{Authors' information}

JRF is Director, Specialty Education, Strategy and Standards in the Office of Specialty Education at the Royal College of Physicians and Surgeons of Canada, and Vice Chair, Education Department of Emergency Medicine, University of Ottawa.

ST is the Associate Director of Education Strategy and Accreditation at the Royal College of Physicians and Surgeons of Canada. She holds a master's degree in Health Administration.

MVZ is a Research Scientist for FAIMER and is involved in various research projects related to international medical graduate issues, including accreditation processes of international medical schools, impact of accreditation on student outcomes, doctor-patient relationships, and crosscultural communication skills. Dr. van Zanten holds a B.A. from the University of Waterloo, Ontario, Canada. She also holds an M.Ed. and a Ph. D in Health Studies from Temple University in Philadelphia, Pennsylvania.

FS has worked as a gynecologist and dean at the OLVG teaching hospital in Amsterdam, the Netherlands. He is also a professor in Health Systems Innovation and Education at the VU University Amsterdam and the Athena Institute for Transdisciplinary Research. FS is the national project leader of the curriculum design for postgraduate training in obstetrics and gynecology, and is currently leading the national reform project for accreditation of residency training and medical practice as chairman of the Legislative College for Accreditation of Residency Training in the Netherlands, where he is closely involved in the regulation of training. FS is the president of the board of the Netherlands Association for Medical Education. He also holds positions in several national and international committees and projects in postgraduate training reform. DB is a Professor in the Faculty of Health Sciences, and holds a crossappointment in the Faculty of Education at Queen's University. She completed a Family Medicine/Emergency Medicine residency from the College of Family Physicians of Canada at Queen's University, and an Emergency Medicine residency from the Royal College of Physicians and Surgeons of Canada at McGill University. She also completed a Master of Health Professions Education degree, a PhD in Curriculum and Instruction as well as a Certificate in Educational Research Methodology, all from the University of Illinois at Chicago.

\section{Funding}

No funding was obtained for this study.

\section{Availability of data and materials}

Not applicable.

\section{Ethics approval and consent to participate}

Not applicable, no human subjects were involved in this study.

\section{Consent for publication}

Not applicable.

\section{Competing interests}

The authors declare that they have no competing interests.

\section{Author details}

${ }^{1}$ Office of Specialty Education, Royal College of Physicians and Surgeons of Canada, Ottawa, Canada. ${ }^{2}$ Department of Emergency Medicine, University of Ottawa, Ottawa, Canada. ${ }^{3}$ Foundation for Advancement of International Medical Education and Research, Philadelphia, PA, USA. ${ }^{4}$ OLVG Teaching Hospital, Amsterdam, The Netherlands. ${ }^{5}$ VU Medical Center, School of Medical Sciences, Amsterdam, The Netherlands. ${ }^{6}$ Athena Institute for Transdisciplinary Research, Amsterdam, The Netherlands. ${ }^{7}$ Department of Emergency Medicine, Queen's University, Kingston, Canada.

Published: 28 September 2020

References

1. Horton R. A new epoch for health professions education. Lancet. 2010;376: 1875-7.

2. World Health Organization. Transforming and scaling up health professional education and training: policy brief $\mathrm{n}$ accreditation of institutions for health professional education. Geneva: WHO; 2013.

3. American Medical Association. History of accreditation of medical education programs. JAMA. 1983;250(12):1502-8.

4. Johnson $\mathrm{V}$. The historical development of accreditation in medical education. JAMA. 1962:181(7):616-9.

5. Flexner A. Medical education in the unites states and Canada. Washington (DC): Science and Health Publications, Inc.; 1910.

6. The Edinburgh declaration. Med Educ. 1988; 22:481-481.

7. Frenk J, et al. Heath professionals for a new century: transforming education to strengthen heath systems in an interdependent world. Lancet. 2010; 376(9756):1923-58.

8. Frank JR, et al. Competence-based medical education: theory to practice. Med Teach. 2010;32:638-45.

9. Nasca T, Philibert I, Brigham T, Flynn T. The next GME accreditation system—rationale and benefits. N Engl J Med. 2012;366(11):1051-6.

10. CanRAC. About CanERA. http://www.canera.ca/canrac/about-e Accessed 18 Nov 2019.

11. Asch DA, et al. How do you deliver a good obstetrician? Outcome based evaluation of medical education. Acad Med. 2014;89(1):24-6.

12. Levitt $K$, et al. Predictors of normal coronary arteries at coronary angiography. Am Heart J. 2013;166:694-700.

13. Wijeysundera H. C et al. impact of system and physician factors on the detection of obstructive coronary disease with diagnostic angiography in stable ischemic heart disease. Circ Cardiovasc Qual Outcomes. 2014;7(5): 648-55.

14. Wenghofer EF, et al. Factors affecting physician performance: implications for performance improvement and governance. Health Policy. 2009;5(2): 141-60.

15. National Academies of Sciences, Engineering, and Medicine, Health and Medicine Division, Board on Global Health, Global Forum on Innovation in Health Professional Education. Exploring the role of accreditation in enhancing quality and innovation in health professions education: proceedings of a 
workshop. Washington (DC): National Academies Press; 2016. Available: https:// www.nap.edu/download/23636 Accessed 18 Nov 2019.

16. Tyrer S, Heyman B. Sampling in epidemiological research. BJPscyh Bull. 2016;40:57-60.

17. World Federation for Medical Education. Accreditation. 2018. Available: http://wfme.org/accreditation/. Accessed 4 April 2018.

18. International Association of Medical Regulatory Authorities. Statement: accreditation of medical education programs. Euless, TX: The Association; 2016. Available from: www.iamra.net/policies Accessed 4 April 2018.

19. Maniate JM. Redesigning a resident program evaluation to strengthen the Canadian residency education accreditation system. Acad Med. 2010;85(7): 1196-202.

20. Andolsek KM, Nagler A, Weinerth JL. Use of an institutional template for annual program evaluation and improvement: benefits for program participation and performance. J Grad Med Educ. 2010;2(2):160-4.

21. Boelen C, Woollard B. Social accountability and accreditation: a new frontier for educational institutions. Med Educ. 2009;43:887-94.

22. Blouin D, Tekian A, Kamin C, Harris IB. The impact of accreditation on medical schools' processes. Med Educ. 2018;52(2):182-91.

23. Boulet J, van Zanten M. Ensuring high-quality patient care: the role of accreditation, licensure, specialty certification and revalidation in medicine. Med Educ. 2014;48(1):75-86.

24. Cueto J, Burch VC, Adnan NA, Afolabi BB, Ismail Z, Jafri W, et al. Accreditation of undergraduate medical training programs: practices in nine developing countries as compared with the United States. Educ Health. 2006;19(2):207-22.

25. Karle H. World Federation for Medical Education Policy on international recognition of medical schools' programme. Ann Acad Med. 2008;37(12): 1041-3.

26. Schirlo C, Heusser R. Quality assurance of medical education: a case study from Switzerland. GMS Z Med Ausbild. 2010;27(2):Doc24.

27. Kelchen R. Higher education accountability. Baltimore: Johns Hopkins University Press; 2018.

28. Accreditation Canada. Health education accreditation [website]. Available: https:/accreditation.ca/health-education-accreditation/ Accessed 18 Nov 2019.

29. Ahn E, Ahn D. Beyond accreditation: excellence in medical education. Med Teach. 2013;36(1):84-5. https://doi.org/10.3109/0142159X.2013.830177 Accessed 18 Nov 2019.

30. Batalden P, Leach D, Swing S, Dreyfus H, Dreyfus S. General competencies and accreditation in graduate medical education. Health Aff (Millwood). 2002;21(5):103-11.

31. Barzansky B, Hunt D, Moineau G, Ahn D, Lai CW, Humphrey H, Peterson L. Continuous quality improvement in an accreditation system for undergraduate medical education: benefits and challenges. Med Teach. 2015;37(11):1032-8.

32. Blouin $D$, Tekian A. Accreditation of medical education programs: moving from student outcomes to continuous quality improvement measures. Acad Med. 2018;93(3):377-83.

33. Gorroll AH, Sirio C, Duffy FD, LeBlond RF, Alguire P, Blackwell TA, et al. A new model for accreditation of residency programs in internal medicine. Ann Intern Med. 2004;140(11):902-9.

34. Pomey M-P, Lemieux-Charles L, Champagne F, Angus D, Shabah A, Contandriopoulos A-P. Does accreditation stimulate change? A study of the impact of the accreditation process on Canadian healthcare organizations. Implement Sci. 2010;5:31 Available: https:// implementationsciencebiomedcentralcom/articles/101186/1748-5908-5-31 Accessed 18 Nov 2019

35. Scrivens E. Putting continuous quality improvement into accreditation: improving approaches to quality assessment. Qual Health Care. 1997;6(4): 212-8.

36. Sweet DB, Vasilias J, Clough L, Davis F, McDonald FS, Reynolds EE, et al. The power of collaboration: experiences from the educational innovations project and implications for the next accreditation system. J Grad Med Educ. 2014;6(3):597-602.

37. Rose SH, Long TR. Accreditation council for graduate medical education (ACGME) annual anesthesiology residency and fellowship program review: a "report card" model for continuous improvement. BMC Med Educ. 2010; 10(13):1-6 Available: www.biomedcentral.com/1472-6920/10/13 Accessed 18 Nov 2019.

38. Abrahamson S. Diseases of the curriculum. J Med Educ. 1978;53(12):951-7.
39. Tamblyn R, et al. Association between licensure examination scores and practice in primary care. JAMA. 2002;288(23):3019-26.

40. Bordage $\mathrm{G}$, et al. Practice indicators of suboptimal care and avoidable adverse events. Acad Med. 2013:88(10):1493-8.

41. Braithwaite J, et al. Health service accreditation as a predictor of clinical and organizational performance: a blinded random, stratified study. Qual Saf Health Care. 2010;19:14-21.

42. Greenfield D, Braithwaite J. Developing the evidence based for accreditation in healthcare organizations: a call for transparency and action. Qual Saf Health Care. 2009;18(3):162-3.

43. Greenfield D, Braithwaite J. Health sector accreditation research: a systematic review. Int J Qual Health Care. 2008;20(3):172-83.

44. Barzannsky B. Comparison of accreditation practices and standards of US Schools of Medicine and Veterinary Medicine. J Vet Med Educ. 2004;32(2): 120-5.

45. Taber, S, et al. A "fit for purpose" framework for medical education accreditation system design. 2019.

46. Akdemir, $\mathrm{N}$, et al. Reflections on the role of continuous quality improvement in accreditation for the 21st century. 2019.

47. Philibert I, Blouin D. Responsiveness to societal needs in postgraduate medical education: the role of accreditation; 2019.

48. Bandiera, $G$, et al. Effective accreditation in postgraduate medical education: from processes to outcomes and back. 2019.

49. Akdemir $\mathrm{N}$, et al. How changing quality management influenced PGME accreditation: a focus on decentralization and quality improvement. BMC Med Educ. 2017;17:98

\section{Publisher's Note}

Springer Nature remains neutral with regard to jurisdictional claims in published maps and institutional affiliations.

Ready to submit your research? Choose BMC and benefit from:

- fast, convenient online submission

- thorough peer review by experienced researchers in your field

- rapid publication on acceptance

- support for research data, including large and complex data types

- gold Open Access which fosters wider collaboration and increased citations

- maximum visibility for your research: over $100 \mathrm{M}$ website views per year

At $\mathrm{BMC}$, research is always in progress.

Learn more biomedcentral.com/submissions 